\title{
Adatom modified shape-controlled platinum nanoparticles towards ethanol oxidation
}

\author{
Carlos Busó-Rogero, Jose Solla-Gullón, Francisco J. Vidal-Iglesias, Enrique Herrero \\ and Juan M. Feliu \\ Instituto de Electroquímica, Universidad de Alicante, Ap. 99 E-03080 Alicante, Spain \\ e-mail:herrero@ua.es
}

\begin{abstract}
Different adatom modified shape-controlled Pt nanoparticles have been prepared and their electrocatalytic properties have been evaluated toward ethanol electrooxidation. Based on previous findings with $\mathrm{Pt}$ model surfaces, $\mathrm{Sn}, \mathrm{Rh}, \mathrm{Ru}$ and $\mathrm{Pb}$ adatoms have been selected as promising surface modifiers. The different adatoms have been gradually incorporated on the surface of the preferentially oriented (100) and (111) Pt nanoparticles under electrochemical conditions. The results obtained in $0.5 \mathrm{M} \mathrm{H}_{2} \mathrm{SO}_{4}$ indicated that, among the selected adatoms, Sn-modified nanoparticles displayed not only a significant shift to negative values on the onset potential of the ethanol oxidation, but also an important decrease on the hysteresis between the positive and negative sweeps. Interestingly, in chronoamperometic measurements at $0.6 \mathrm{~V}$, the oxidation enhancement factors have been found to be dependent on the surface structure of the Pt nanoparticles. On the other hand, $\mathrm{Ru}$ and $\mathrm{Pb}$-modified $\mathrm{Pt}$ nanoparticles only presented a rather small oxidation enhancement, whereas the activity of the Rh-modified Pt nanoparticles clearly diminished. In alkaline solutions, the oxidation mechanism changes, and the adsorption of $\mathrm{Rh}, \mathrm{Sn}$ and $\mathrm{Pb}$ on the platinum surfaces just displays small catalytic effect at lower
\end{abstract}


coverage for the potential onset in the voltammetric experiments. Ru adsorption does not present any positive effect over the reaction.

Keywords: Ethanol oxidation, electrocatalysis, Pt-based electrodes, tin, rhodium, ruthenium, lead, shape-controlled nanoparticles.

\section{Introduction}

Nowadays, the studies about new energy sources are gaining momentum due to the depletion of fossil fuels. One of these alternative energy sources is the development of fuel cells, which can obtain energy simply from the reaction between a fuel and an oxidant species (usually oxygen). Fundamental research in fuel cells is usually centered in the material used for manufacturing the catalyst and its electrocatalytic response to the desired reaction on the cathode or on the anode [1]. As a catalyst, platinum is a good choice due to its well-known catalytic properties. Different chemicals have been selected as possible candidates for using as a fuel in the anode, from the most typical hydrogen to some small organic molecules such as formic acid, methanol or ethanol. Among these organic molecules, ethanol is one of the most studied fuels [2], because it presents some advantages as the easiness for obtaining it from biomass in addition to its low toxicity or its high energy density for the complete oxidation to $\mathrm{CO}_{2}$, where 12 electrons are exchanged according with the reaction:

$$
\mathrm{CH}_{3} \mathrm{CH}_{2} \mathrm{OH}+3 \mathrm{H}_{2} \mathrm{O} \longrightarrow 2 \mathrm{CO}_{2}+12 \mathrm{H}^{+}+12 \mathrm{e}^{-}
$$

Nevertheless, this reaction is not as simple as appears in the general equation presented above, because parallel reactions can occur, decreasing the efficiency of the complete oxidation, the desired route. When using platinum as catalyst, this reaction has shown to be structure sensitive [3], that is, depending on the arrangement of the platinum 
atoms on the surface of the electrode, the reactivity changes. On this electrode, ethanol oxidation mechanism has a dual-path mechanism:

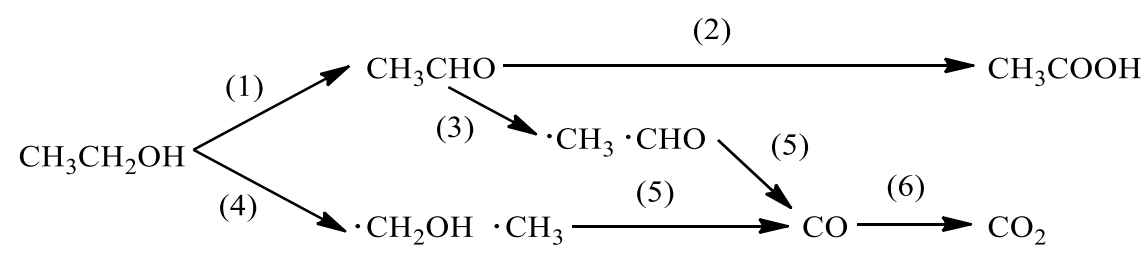

Step (1) of the scheme corresponds to the ethanol oxidation to acetaldehyde, whereas step (2) is the acetaldehyde oxidation to acetic acid. These two reactions compose the route known as ethanol incomplete oxidation. Step (3) and step (4) show the C-C bond scission from acetaldehyde and ethanol respectively, needed to achieve $\mathrm{CO}_{2}$ formation. However, previous to the complete oxidation, $\mathrm{CO}$ is formed and poisons the catalyst surface. At high potentials, this $\mathrm{CO}$ is finally oxidized to $\mathrm{CO}_{2}$. On $\mathrm{Pt}$ (111) electrodes, only acetic acid is formed without poison formation. However, on Pt (100) and Pt (110) electrodes, $\mathrm{C}-\mathrm{C}$ bond scission is observed and $\mathrm{CO}$ is formed, blocking the surface for further reaction at low potentials $[3,4]$. On the other hand, the oxidation in alkaline solutions leads to the almost exclusive production of acetate and negligible amounts of $\mathrm{CO}$ and $\mathrm{CO}_{2}$ (carbonate at higher $\mathrm{pH}$ values) [5].

The problem of using platinum is its high price. One option for reducing the cost of platinum is to use it in the form of nanoparticles, with high active area, thus allowing the use of lower amounts of platinum. In addition, most of the reactions in fuel cell applications are structure sensitive. Thus, a careful selection of the surface structure of the nanoparticle can lead to an increase in the electrocatalysis. This can be achieved by synthesizing shape-controlled platinum nanoparticles, as has been done for the oxidation of organic molecules (formic acid, methanol, ethanol, glycerol and ammonia [6-9]) or oxygen reduction [10-12]. An additional increase in the catalytic activity of the Pt can be obtained by the modification of the electronic properties by forming alloys. 
Focusing on ethanol oxidation, alloys composed of platinum and other metals, such as $\mathrm{Sn}, \mathrm{Ru}, \mathrm{Rh}, \mathrm{Mo}$ or $\mathrm{Cu}$, show improved selectivity to the $\mathrm{C}-\mathrm{C}$ bond scission and/or enhanced activity for the oxidation of $\mathrm{CO}$, so that the total electrocatalytic activity is increased [13-19]. However, for a better understanding of the actuation mechanism of the additional element in the Pt alloys, the controlled deposition of foreign adatoms on platinum with a well-known surface structure is considered as a suitable approach for this study. With this approach, a large amount of different modified platinum surfaces can be tested due to the easiness of preparation of electrodes with variable composition [20]. Additionally, the test of the different modifications can be carried out in similar conditions, which allows a better comparison between different modifiers.

The metals chosen for depositing on Pt surface and study their electrocatalytic effect towards ethanol oxidation were tin, rhodium, ruthenium and lead. In previous studies, Sn and $\mathrm{Ru}$ deposition on stepped surfaces showed some enhancement for the oxidation to $\mathrm{CO}_{2}[21,22]$, whereas Pt deposited on Rh electrodes also shows increased activity for the C-C bond scission [23]. In addition, some works have demonstrated the improvement in the carbonate formation when $\mathrm{Pb}$ atoms are adsorbed on polycrystalline $\mathrm{Pt}$ surfaces in alkaline solutions [24, 25].

In this work, fundamental studies about the electroactivity of the $\mathrm{Sn}, \mathrm{Rh}, \mathrm{Ru}$ and $\mathrm{Pb}$-modified platinum nanoparticles, specifically in (100) and (111) Pt nanoparticles, for ethanol oxidation are reported in two different $\mathrm{pH}$ values (acidic and alkaline solutions). These two types of nanoparticles have been selected because they represent two different paradigms for the ethanol oxidation reaction. As aforementioned, the (111) plane of Pt is inactive for the cleavage of the $\mathrm{C}-\mathrm{C}$ bond, yielding acetic acid/acetate both in acid and alkaline solutions, whereas the (100) plane is active for this process in acidic conditions. Thus, the effect of the adatoms on both reaction paths can be analyzed. The studies will 
be carried out using voltammetric and chronoamperometric techniques, which will allow the best conditions to achieve the highest electrocatalytic activity ( $\mathrm{pH}$ and composition) to be determined for the studied reaction.

\section{Experimental}

Preferential cubic and octahedral Pt nanoparticles were used in this study. According to the observed shape by TEM, these nanoparticles should contain a high fraction of (100) and (111) domains, respectively [6, 26]. For that reason, they have been named (100) Pt nanoparticles and (111) Pt nanoparticles. These Pt nanoparticles were prepared according to the colloidal method [27]. In brief, solutions containing $\mathrm{K}_{2} \mathrm{PtCl}_{4}$ for (100) nanoparticles and $\mathrm{H}_{2} \mathrm{PtCl}_{6}$ for (111) Pt nanoparticles were reduced using $\mathrm{H}_{2}$ in controlled conditions to form nanoparticles. After that, nanoparticles were cleaned with $\mathrm{NaOH}$ pellets and dispersed in water. Additional details on the synthesis can be found in ref. [7, 26].

Pt nanoparticles were deposited on a glassy carbon support, and dried during 15-20 minutes in Ar atmosphere. After the drying, Pt nanoparticle samples were cleaned using $\mathrm{CO}$ adsorption and stripping, but avoiding the used of high potential values to preserve the surface structure order. Cyclic voltammetry was used to assure the correct cleaning of the platinum nanoparticles. The active area was measured from the hydrogen adsorption charge after double layer subtraction using the reported reference value of 0.23 $\mathrm{mC} \mathrm{cm} \mathrm{cm}^{-2}[28]$.

The deposition of $\mathrm{Sn}, \mathrm{Rh}, \mathrm{Ru}$, and $\mathrm{Pb}$ on the nanoparticles was carried out from solutions containing $\mathrm{SnSO}_{4}\left(\right.$ Merck $\left.^{\circledR}\right)$, hydrated $\mathrm{RhCl}_{3}\left(\right.$ Aldrich $\left.{ }^{\circledR}\right)$, hydrated $\mathrm{RuCl}_{3}$ $\left(\right.$ Fluka $\left.^{\circledR}\right)$ and $\mathrm{Pb}\left(\mathrm{NO}_{3}\right)_{2}\left(\right.$ Aldrich $\left.^{\circledR}\right)$, all of them with a purity higher than $99.8 \%$. A very low concentration of the metal precursor was used $\left(10^{-5}-10^{-6} \mathrm{M}\right.$ in $\left.0.5 \mathrm{M} \mathrm{H}_{2} \mathrm{SO}_{4}\right)$, so that 
the deposition of the metal is slow and diffusion controlled. This allows the change of the adatom coverage on the surface to be followed by using the cyclic voltammogram recorded between 0.06 and $0.8 \mathrm{~V}$ at $0.05 \mathrm{~V} \mathrm{~s}^{-1}$. The increase in the adatom coverage leads to the decrease in the hydrogen adsorption charge, as shown in previous experiments with $\mathrm{Pd}, \mathrm{Sb}, \mathrm{Bi}$ or $\mathrm{Tl}$ [29-32]. Thus, the coverage can be determined using the following expression:

$$
\theta_{x}=1-\theta_{H}=\frac{q_{H}^{0}-q_{H}^{x}}{q_{H}^{0}}
$$

where $\mathrm{qH}^{0}$ and $\mathrm{qH}^{\mathrm{x}}$ are the hydrogen adsorption charges for bare and adatom modified $\mathrm{Pt}$ nanoparticles. This method for measuring the adatom coverage is valid for all the metals used in this work except for $\mathrm{Rh}$, where new peaks appear in the voltammetric profile in the hydrogen adsorption region, due to hydrogen adsorption on rhodium. This prevents an accurate determination of the $\mathrm{Rh}$ coverage and for that reason an increasing order of coverage is only indicated.

Once completed the preparation of the modified electrodes, a cyclic voltammogram or a chronoamperogram were recorded in $0.2 \mathrm{M} \mathrm{CH}_{3} \mathrm{CH}_{2} \mathrm{OH}$ in $0.5 \mathrm{M} \mathrm{H}_{2} \mathrm{SO}_{4}$ or $0.1 \mathrm{M}$ $\mathrm{NaOH}$ as supporting electrolyte, depending if we work in acidic or alkaline solutions. Ethanol absolute (Merck ${ }^{\circledR}$ p.a.), $\mathrm{H}_{2} \mathrm{SO}_{4}\left(\right.$ Merck $^{\circledR}$ Suprapur 96\%) and $\mathrm{NaOH}$ monohydrate $\left(99.99 \%\right.$, Merck ${ }^{\circledR}$ Suprapur) were used for preparing the solutions together with ultrapure water (Elga Purelab Ultra 18.2 M $\Omega \mathrm{cm}$ ).

All the experiments were carried out at room temperature in a three-cell electrochemical cell, using a Pt wire as a counter-electrode, and reversible hydrogen (N50, Air Liquide) as reference electrode (RHE). Ar (N50, Air Liquide) was employed for deoxygenating the solutions. Cyclic voltammetry and chronoamperometric experiments were performed using a waveform generator (EG\&EG PARC 175), together with a potentiostat (eDAQ EA161) and a digital recorder (eDAQ ED401). 


\section{Results and discussion}

\subsection{Electrochemical characterization of modified Pt nanoparticles}

Previous to the ethanol oxidation studies, a cyclic voltammogram is recorded to characterize the $\mathrm{Pt}$ nanoparticles samples in $0.5 \mathrm{M} \mathrm{H}_{2} \mathrm{SO}_{4}$. This voltammogram is considered as a fingerprint of the Pt surfaces and allows the characterization of the different domains present on the nanoparticle samples. This electrochemical characterization is presented in Fig. 1 and Fig. $2(\Theta=0)$. Very briefly, the (111) nanoparticles show a wave due to the adsorption of sulfate on the (111) domains between 0.45 and $0.6 \mathrm{~V}$, whereas the adsorption processes on the (100) ordered domains produces a defined signal at $c a$. $0.37 \mathrm{~V}$. Additionally, monodimensional domains such as edges, steps or defects with (110) and (100) symmetry appear as peaks at 0.125 and $0.26 \mathrm{~V}$, respectively. A more exhaustive description of the voltammetric profiles of these shapecontrolled Pt nanoparticles can be found in references $[26,33]$.

The changes of the profiles upon the adsorption of the different adatoms have been also followed using voltammetry. Fig. 1 and Fig. 2 show the evolution of the voltammetric profile for both $\mathrm{Pt}$ nanoparticle samples after being modified by $\mathrm{Sn}, \mathrm{Rh}, \mathrm{Ru}$ and $\mathrm{Pb}$ in 0.5 $\mathrm{M} \mathrm{H}_{2} \mathrm{SO}_{4}$. For Sn, the first stage in the deposition is the adsorption on monodimensional domains as can be observed by the diminution of the peaks associated with those sites, whereas the (111) ordered domains are only covered at high adatom coverages. This behavior is in agreement with previous experimental and theoretical results using stepped (111) surfaces for tin [21, 34-36] or for other adatoms with lower electronegativity values than $\mathrm{Pt}[37,38]$. In addition, an irreversible redox process was observed around 0.6-0.7 $\mathrm{V}$, assigned to the surface oxidation at tin atoms. The same feature is clearly observed for Sn-modified Pt nanoparticles with high adatom coverage in this range of potential. No 
additional peaks due to the adsorption of tin can be observed between 0.1 and $0.4 \mathrm{~V}$, which allow the coverage to be determined by the decrease of the hydrogen adsorption charge.

When $\mathrm{Rh}$ is adsorbed on the Pt surface, the voltammetric profiles progressively evolve until the typical features of Rh in this medium appear [39]. Thus, the hydrogen adsorption region shifts to negative potential values and the onset for oxide formation takes place at lower potential values. For the Rh-modified (111) Pt nanoparticles, Fig. 2, two irreversible peaks can be seen at $0.16 \mathrm{~V}$ and $0.13 \mathrm{~V}$, also observed in $\mathrm{Rh} / \mathrm{Pt}(111)$ [40, 41]. The $\mathrm{Rh}$ adsorption produces an overlapping between the two hydrogen adsorption regions in $\mathrm{Pt}$ and $\mathrm{Rh}$, preventing an accurate determination of the $\mathrm{Rh}$ coverage. For this reason, as it is mentioned above, specific coverage values for these modified electrodes are not given, being simply ordered in increasing coverage values.

For $\mathrm{Ru}$ adsorption over the $\mathrm{Pt}$ nanoparticles, the behavior is similar to the $\mathrm{Sn}$ deposition, thus allowing an easy follow up of the Ru coverage with the decrease of hydrogen adsorption peaks [22, 42, 43]. Some additional Ru adsorption characteristics for sulfuric acid solutions appear in Fig. 1, as the small peak at $0.22 \mathrm{~V}$ assigned to the sulfate adsorption on large-ordered (100) domains close to $\mathrm{Ru}$ atoms, in addition to the current increase from $0.6 \mathrm{~V}$ due to the $\mathrm{Ru}$ oxidation, which takes place at high potentials.

Finally, $\mathrm{Pb}$ adsorption on $\mathrm{Pt}$ surfaces is not very stable, and the adatom can be desorbed only with a few cycles at relative low potentials [44]. Thus, high coverage values cannot be achieved. However, no additional peaks are observed due to $\mathrm{Pb}$ redox processes at lower potentials, so the usual method of the decrease in hydrogen adsorption charge can be used for follow the $\mathrm{Pb}$ coverage. The voltammetric curves are similar to others reported for $\mathrm{Pb}$ adsorption on polycrystalline surfaces [25], observing also an increase in the current around $0.6 \mathrm{~V}$ due to the $\mathrm{OH}$ adsorption on $\mathrm{Pb}$ atoms. 


\subsection{Ethanol oxidation in acidic medium}

Fig. 3 shows the voltammetric profiles for ethanol oxidation on bare and adatom decorated (100) Pt nanoparticles. For the bare nanoparticles, the prominent peak at $0.8 \mathrm{~V}$ is due to the oxidation of $\mathrm{CO}$ layer from the $\mathrm{C}-\mathrm{C}$ bond cleavage of ethanol, more favorable in (100) ordered domains, and the subsequent activation of the surface for the direct oxidation to acetic acid and to $\mathrm{CO}_{2}$ [7]. This fact leads to a large hysteresis between the positive and negative scan directions. Thus, in the negative scan direction, larger currents are observed, due to the absence of $\mathrm{CO}$ accumulation on the surface below $0.5 \mathrm{~V}$, which allows the oxidation of ethanol on the surface. On the other hand, Fig. 4 displays the voltammetric response for (111) Pt nanoparticles. As can be seen, the hysteresis is very low, due to the preference of the (111) ordered domains for the incomplete oxidation of ethanol to acetic acid [3].

Small differences in the voltammograms recorded in the absence of the adatoms for the same type of nanoparticles are observed, especially regarding the maximum current density. These effects are due to changes in the spatial distribution of the deposit. Although the amount of nanoparticles is similar in all cases, some agglomeration of the nanoparticles may take place during the drying process. As has been shown [45], nanoparticle agglomeration leads to deposits in which some nanoparticles are not active for the oxidation since the incoming flux of ethanol is consumed in the outer layers of the deposit, leading to lower current densities than the reported previously [7]. Since the main objective of the manuscript is to understand the role of the adatoms in the oxidation mechanism, the voltammograms for the different coverages for a given adatom were recorded with the same sample, so that currents can be compared and the different effects of the adatoms can be rationalized. 
Among all the tested adatoms, the one that has a clear negative impact in the oxidation of ethanol is Rh. In all cases, the current diminishes significantly and no change in the onset potential can be detected. Although it has been reported that PtRh alloys increase the $\mathrm{CO}_{2}$ /acetaldehyde ratio in ethanol oxidation $[15,23]$, the net effect observed here is a diminution of the total current. At this respect, it is worth noting that $\mathrm{Rh}$ atoms are exclusively adsorbed at the surface of Pt nanoparticles, that is, Rh decorated Pt surface is formed, whose behavior can be different from that observed for a PtRh surface alloy. Although it has been proposed that RhPt alloys catalyze the C-C bond splitting [15], there is not a significant increase in the total currents. This is probably due to the low activity of the $\mathrm{Rh}$ atoms for the dehydrogenation of small organic molecules. The net result of $\mathrm{Rh}$ is a diminution of the total current, because the increase in the $\mathrm{C}-\mathrm{C}$ bond splitting rate does not compensate the diminution of the rate in the other steps of the reaction. Finally, for the highest coverage, the curves resemble those obtained in pure Rh electrodes [46], that are known to be much less active than Pt for ethanol electrooxidation.

Ruthenium on platinum surfaces is known to catalyze the oxidation of $\mathrm{CO}$ which appears as intermediate on oxidation processes of small organic molecules. For that reason, previous results for ethanol oxidation in Pt stepped surfaces [22, 47] and for methanol oxidation in platinum surfaces [43, 48] show the improvement of the electrocatalytic activity. In the case of ethanol, $\mathrm{Ru}$ is not affecting other steps in the reaction, that is, is not enhancing the $\mathrm{C}-\mathrm{C}$ bond cleavage or the formation of acetic acid as has been shown with single crystal electrodes [22]. Thus, for the (100) Pt nanoparticles, a lower potential onset for ethanol oxidation is observed in figure 3, since Ru catalyzes the oxidation of $\mathrm{CO}$ formed at low potential values. For the (111) Pt nanoparticles, since the activity for the $\mathrm{C}-\mathrm{C}$ bond cleavage is low, the onset does not change significantly. It should be stressed that the observed effects of Ru deposition for the nanoparticles are 
smaller than those recorded for the Ru decorated stepped surfaces. In this latter case, the $\mathrm{Ru}$ adatoms are deposited neighboring the sites active for the $\mathrm{C}-\mathrm{C}$ bond cleavage, so that, their activity is maximized. For the nanoparticles, such control is not possible, and thus its effect is lower. Additionally, the progressive current decrease with increasing coverages indicates a negligible activity of the other steps in the reaction and the poor catalytic behavior for these surfaces.

The deposition of $\mathrm{Pb}$ on $\mathrm{Pt}$ surfaces in acidic solutions improves the onset potential for formic acid oxidation $[49,50]$. In the case of ethanol, a small increase in the currents is observed for low and intermediate coverages. Additionally, the shape of the voltammogram remains almost unaffected by the presence of lead on the surface of the nanoparticles. This fact means that lead on the Pt surface catalyzes the oxidation of ethanol but it does not change significantly the product distribution. Additionally, the huge current decay with the other adatoms at the maximum coverage is not observed for lead because of the poor stability of these surfaces [44], that prevent higher coverages for the Pb-modified Pt nanoparticles.

Clearly, the most significant catalytic effects for ethanol oxidation are observed for the Sn modified nanoparticles. For low and medium Sn coverages, the onset potential for ethanol oxidation is shifted to negative values, independently of the platinum nanoparticle samples used. This current increase at low potentials is related to the catalysis of the CO adsorbed to $\mathrm{CO}_{2}$, as it is confirmed with the disappearance of the prominent peak in the (100) Pt nanoparticles characteristic of the CO presence. This fact can be explained with the bifunctional mechanism $[21,51]$, where the catalysis $\mathrm{CO} / \mathrm{CO}_{2}$ is enhanced with $\mathrm{OH}$ adsorbed on Sn atoms. Nevertheless, for (100) Pt nanoparticles the onset potential seems to be unaltered for coverage values above 0.3, whereas in (111) Pt nanoparticles (Fig. 4) continuously decreases for increasing coverages. This effect can be explained by the 
competitive adsorption between $\mathrm{CO}$ and tin atoms, which produces a decrease in the free sites where ethanol oxidation occurs. For this reason, mainly for (100) Pt nanoparticles, the catalytic effect of $\mathrm{Sn}$ remains constant after coverages of 0.3 , whereas in (111) $\mathrm{Pt}$ nanoparticles sample, where the $\mathrm{CO}$ formation rate is significantly lower, the onset potential for ethanol oxidation still diminishes for high adatom coverages. In addition, for this sample, the increase in the total currents and the diminution of the hysteresis confirms that the presence of tin adsorbed in (111) ordered domains catalyzed the incomplete ethanol oxidation to acetic acid [21]. At maximum coverage, activity decays drastically due to the absence of free sites necessary for catalyzing the ethanol oxidation reaction.

Since tin is the most active adatom in the catalysis, it is important to deepen in the understanding of its effects in the reaction. In figure 5, the ratio of the currents recorded in the positive going-sweep between the modified nanoparticles with the highest activity (coverage close to 0.5) and the unmodified nanoparticles is shown. Two regions can be observed in these curves, especially for the (111) Pt nanoparticles. At low potentials, the increase is due to the catalysis of $\mathrm{CO}$ oxidation. In this region, the improvement factor is slightly better in (111) Pt nanoparticles, probably due to a small increase in the production of $\mathrm{CO}$ or the catalysis of the oxidation for the $\mathrm{CH}_{3}$ fragment on the free Pt sites. On the (100) Pt nanoparticles, this latter process is less possible because the $\mathrm{CO}$ coverage is higher. At higher potentials (above $0.75 \mathrm{~V}$ ), when all the adsorbed CO molecules have been effectively oxidized to $\mathrm{CO}_{2}$, the currents of the modified and unmodified samples become essentially similar independently of the Pt nanoparticles used.

Chronoamperometric results are presented in Figure 6 for evaluating the variance of the activity and assure the stability of the modified electrodes with time. In this experiment, after a step to $0.9 \mathrm{~V}$ for oxidizing the $\mathrm{CO}$ formed at low potentials, the potential is set at $0.6 \mathrm{~V}$ to record the evolution of the oxidation currents. In all cases, a 
significant decay in the currents is measured after $10 \mathrm{~min}$. This decay should be due to the accumulation of $\mathrm{CO}$ on the surface, because the rate of the $\mathrm{C}-\mathrm{C}$ bond cleavage step is higher than the $\mathrm{CO}$ oxidation rate. Comparing (100) and (111) Pt nanoparticles, the increase of the currents after $10 \mathrm{~min}$ with respect to those recorded in absence of tin is higher for the (111) Pt nanoparticles. This effect can be easily explained by the higher activity for the C-C bond splitting of the (100) Pt nanoparticles. Thus, the stationary CO coverage will be higher, that is, there are less free Pt sites, and consequently lower currents are recorded at long times. For the (111) Pt nanoparticles, the higher number of free Pt available sites and the catalytic effect of tin for the oxidation of ethanol to acetic acid results in higher currents [21].

The currents at $600 \mathrm{~s}$ of the chronoamperometric curves vs. tin coverage are plotted in Fig. 7 for the two Pt nanoparticles samples used. Initially, currents increase with the addition of tin on the surface. For (100) Pt nanoparticles, at coverage values higher than 0.3, it diminishes, whereas for the (111) Pt nanoparticles, it reaches the maximum and stable value for coverages above 0.5 . At higher tin coverages, currents increase but very slightly. Again, the competitive catalytic effect of tin for oxidation of $\mathrm{CO}$ and the oxidation of ethanol to acetic acid explains this behavior.

\subsection{Ethanol oxidation in alkaline solutions.}

Similarly to that shown in Fig. 3 and 4, the study of the effect of the adatoms towards the oxidation of ethanol in alkaline conditions is shown in Figs. 8 and 9. Due to the high activity above $0.7 \mathrm{~V}$, the voltammograms are affected by the diffusion of the electroactive species through the catalyst layers and also by ohmic drop, due to the large currents and the lower conductivity of the alkaline solutions [5, 45]. However, for practical applications, currents above $0.7 \mathrm{~V}$ are not interesting, since the voltage obtained 
in a fuel cell would be negligible. For that reason, only onset potentials will be analyzed in this case.

It was shown before that the solution $\mathrm{pH}$ has a strong influence on the oxidation mechanism, considerably modifying the ratio between the products formed after changing from acidic to alkaline solutions $[5,52]$. As previously mentioned, the main product in the oxidation for the different Pt single crystal electrodes and nanoparticles is acetate, whereas the amount of carbonate detected can be considered negligible. This drastic change in the oxidation mechanism has been related to changes in the adsorption modes of ethanol. Thus, ethanol adsorption on platinum in alkaline media is proposed to occur through the oxygen atom and not through the $\mathrm{C} 1$ atom of ethanol $[52,53]$. Since the cleavage of the $\mathrm{C}-\mathrm{C}$ bond requires a bidentate adsorption mode with the $\mathrm{C} 1$ and $\mathrm{C} 2$ atoms bonded to the surface, the adsorption through the oxygen atom hinders this process. On the other hand, the oxidation to acetate requires the transfer of an $\mathrm{OH}$ group to the $\mathrm{C} 1$ atom. In this medium, the results with single crystal electrodes show that ethanol oxidation to acetic acid takes place when $\mathrm{OH}$ is adsorbed on the Pt surface. Thus, the main product is acetate, and $\mathrm{CO}$ formation is quasi negligible in these conditions. This fact determines the effect of the adatoms. Ru, which has high oxophilicity, could have contributed to two different steps in the reaction mechanism: to the oxidation of $\mathrm{CO}$ to $\mathrm{CO}_{2}$ and to the oxidation of acetaldehyde to acetic acid/acetate, since both steps require the transfer of an oxygen group. As aforementioned, $\mathrm{CO}$ is not detected in alkaline solutions, and therefore, this step cannot be catalyzed by Ru. On the other hand, the complex nature of the oxidation process of $\mathrm{Ru}$, yielding a mixture of hydroxides and oxides, whose ratio depends on the electrode potential, prevents an effective catalytic effect on this second step (acetaldehyde to acetate). In the positive scan direction and at low potentials (inset of fig. 8 and 9), the current is almost independent of the Ru coverage. 
However, as the potential is increased, a significant diminution is observed. This is probably due to a progressive transformation of Ru hydroxides to oxides, which are not active for the catalysis. Since this process is irreversible, in the negative scan direction, the currents at low potentials diminish with the Ru coverage. Consequently, Ru adatoms, the role of which is the catalysis of the $\mathrm{CO}$ oxidation to $\mathrm{CO}_{2}$, do not show any enhancement for the oxidation in alkaline conditions, acting almost as a pure third body for the reaction.

On the other hand, low $\mathrm{Rh}, \mathrm{Pb}$ or $\mathrm{Sn}$ coverages show very small effects on the oxidation of ethanol in this medium. As can be seen, the increase of the currents for low coverages is small and the only net effect is a lower onset for low adatom coverages. At higher coverages for those adatoms, total currents at any potential decrease. Previous results for $\mathrm{Pb}$ deposited on polycrystalline platinum electrodes showed a significant increase in the currents in alkaline solutions $[24,25]$. In this case, a lower onset for the oxidation is observed mainly for the (100) Pt nanoparticles. According with the references cited, $\mathrm{OH}$ adsorption on $\mathrm{Pb}$ atoms takes place at potentials around $0.5-0.6 \mathrm{~V}$, lower than on platinum, allowing ethanol to be oxidized at more negative potentials. Thus, it can be proposed that these adatoms act as a bifunctional catalyst by facilitating the transfer of the $\mathrm{OH}$ to the adsorbed ethanol molecule, which compensates the lower amount of Pt free sites due to the adatom coverage. However, the large increase previously observed with the $\mathrm{Pt}-\mathrm{Pb}$ combined surfaces is not achieved in these conditions, probably related with differences in the deposition method and the low coverages reached due to the poor stability of $\mathrm{Pb}$ adsorbed on Pt surfaces [44]. At higher coverages, current decreases, since the small increase of the activity due to the deposition of the adatom does not compensate the loss of the activity due to the blockage of platinum sites by the adatom. 
For Sn, which also has high oxophilicity, the observed behavior is better than that of $\mathrm{Ru}$, probably related to the different electrochemistry of the oxides/hydroxides. In this case, the transfer of the $\mathrm{OH}$ takes place in the whole potential range, which results in currents that are almost independent of the Sn coverage. This suggests that there is no significant transformation of the hydroxides into oxides in this potential range, unlike what is observed for Ru.

\section{Conclusions}

The electrocatalytic properties of clean cubic and octahedral platinum nanoparticles modified with $\mathrm{Sn}, \mathrm{Rh}, \mathrm{Ru}$ and $\mathrm{Pb}$ adatoms have been evaluated for ethanol oxidation reaction in both acidic and alkaline media, using cyclic voltammetry and chronoamperometry. The results indicate that for the Sn-modified Pt nanoparticles, a clear enhancement of both the onset potential and hysteresis is observed in acidic medium. In addition, this enhancement is also dependent on the surface structure of the Pt nanoparticles. The current increment at lower potentials for Sn-modified Pt nanoparticles in acidic solutions is assigned to the catalysis of $\mathrm{CO}$ adsorbed to $\mathrm{CO}_{2}$ where Sn atoms provide the $\mathrm{OH}$ needed to complete the oxidation. Interestingly, the (111) $\mathrm{Pt}$ nanoparticles maintain the catalytic effect for higher coverages compared with (100) Pt nanoparticles because of the lower competition with Sn atoms for the Pt free sites where takes place the reaction. At higher coverages, both samples enhance the acetic acid formation. In similar conditions, Ru-modified Pt nanoparticles only favors the oxidation of $\mathrm{CO}$ to $\mathrm{CO}_{2}$ at lower potentials, without any effect for the $\mathrm{C}-\mathrm{C}$ bond split or the acetic acid formation. Finally, Pb-modified Pt modified surfaces improve slightly the ethanol

oxidation but with the same product distribution, whereas $\mathrm{Rh}$ adsorbed on $\mathrm{Pt}$ nanoparticles has a negative effect over ethanol oxidation reaction. 
In alkaline solutions, the main product in the oxidation is acetate, with negligible

$\mathrm{CO}$ formation. Thus, $\mathrm{Ru}$ atoms adsorbed on platinum nanoparticles, which major effect is to catalyze the $\mathrm{CO}$ oxidation, does not affect ethanol oxidation in these conditions. However, $\mathrm{Sn}, \mathrm{Rh}$ and $\mathrm{Pb}$-modified platinum nanoparticles show a very small improvement of the potential onset. This effect is related to the $\mathrm{OH}$ adsorption on the adatom surfaces at lower potentials, favoring ethanol oxidation to acetate by a bifunctional mechanism.

\section{Acknowledgments}

This work has been financially supported by the Ministerio de Economía y Competitividad (project CTQ2013-44083-P) and Generalitat Valenciana (project PROMETEOII/2014/013).

\section{References}

[1] M.T.M. Koper, Fuel Cell Catalysis: A Surface Science Approach, John Wiley \& Sons, Hoboken, New Jersey, 2009.

[2] E. Antolini, J. Power Sources 170 (2007) 1.

[3] F. Colmati, G. Tremiliosi-Filho, E.R. Gonzalez, A. Berna, E. Herrero, J.M. Feliu, Faraday Discuss. 140 (2008) 379.

[4] F. Cases, M. López-Atalaya, J.L. Vázquez, A. Aldaz, J. Clavilier, J. Electroanal. Chem. 278 (1990) 433.

[5] C. Busó-Rogero, E. Herrero, J.M. Feliu, ChemPhysChem 15 (2014) 2019.

[6] J. Solla-Gullón, F.J. Vidal-Iglesias, A. López-Cudero, E. Garnier, J.M. Feliu, A. Aldaz, Phys. Chem. Chem. Phys. 10 (2008) 3689.

[7] C. Buso-Rogero, V. Grozovski, F.J. Vidal-Iglesias, J. Solla-Gullon, E. Herrero, J.M. Feliu, J. Mater. Chem. A 1 (2013) 7068.

[8] J. Monzo, Y. Malewski, F.J. Vidal-Iglesias, J. Solla-Gullon, P. Rodriguez, ChemElectroChem 2 (2015) 958.

[9] F.J. Vidal-Iglesias, J. Solla-Gullón, P. Rodríguez, E. Herrero, V. Montiel, J.M. Feliu, A. Aldaz, Electrochem. Commun. 6 (2004) 1080.

[10] J. Hernández, J. Solla-Gullón, E. Herrero, J.M. Feliu, A. Aldaz, J. Nanosci. Nanotechnol. 9 (2009) 2256.

[11] C.M. Sanchez-Sanchez, J. Solla-Gullon, V. Montiel, Electrocatalysis at nanoparticles, in: Electrochemistry: Volume 11 - Nanosystems Electrochemistry, vol. 11, The Royal Society of Chemistry, 2013, pp. 34. 
[12] H. Erikson, A. Sarapuu, N. Alexeyeva, K. Tammeveski, J. Solla-Gullón, J.M. Feliu, Electrochim. Acta 59 (2012) 329.

[13] C. Lamy, S. Rousseau, E.M. Belgsir, C. Coutanceau, J.M. Leger, Electrochim. Acta 49 (2004) 3901.

[14] N. Fujiwara, K.A. Friedrich, U. Stimming, J. Electroanal. Chem. 472 (1999) 120.

[15] J.P.I. de Souza, S.L. Queiroz, K. Bergamaski, E.R. Gonzalez, F.C. Nart, J. Phys. Chem. B 106 (2002) 9825.

[16] F. Colmati, E. Antolini, E.R. Gonzalez, J. Alloys Compd. 456 (2008) 264.

[17] A.O. Neto, M.J. Giz, J. Perez, E.A. Ticianelli, E.R. Gonzalez, J. Electrochem. Soc. 149 (2002) A272.

[18] M. Ammam, E.B. Easton, J. Power Sources 222 (2013) 79.

[19] W. Zhou, Z. Zhou, S. Song, W. Li, G. Sun, P. Tsiakaras, Q. Xin, Appl Catal BEnviron 46 (2003) 273.

[20] V. Climent, N. García-Aráez, J.M. Feliu, Clues for the Molecular-Level Understanding of Electrocatalysis on Single-Crystal Platinum Surfaces Modified by pBlock Adatoms, in: Fuel Cell Catalysis, John Wiley \& Sons, Inc., 2008, pp. 209.

[21] V. Del Colle, J. Souza-Garcia, G. Tremiliosi, E. Herrero, J.M. Feliu, Phys. Chem. Chem. Phys. 13 (2011) 12163.

[22] V. Del Colle, A. Berna, G. Tremiliosi, E. Herrero, J.M. Feliu, Phys. Chem. Chem. Phys. 10 (2008) 3766.

[23] V. Del Colle, V. Grozovski, E. Herrero, J.M. Feliu, ChemCatChem 5 (2013) 1350.

[24] Q.G. He, B. Shyam, K. Macounova, P. Krtil, D. Ramaker, S. Mukerjee, J. Am. Chem. Soc. 134 (2012) 8655.

[25] P.A. Christensen, S.W.M. Jones, A. Hamnett, Phys. Chem. Chem. Phys. 15 (2013) 17268.

[26] J. Solla-Gullón, P. Rodríguez, E. Herrero, A. Aldaz, J.M. Feliu, Phys. Chem. Chem. Phys. 10 (2008) 1359.

[27] T.S. Ahmadi, Z.L. Wang, T.C. Green, A. Henglein, M.A. El-Sayed, Science 272 (1996) 1924.

[28] Q.S. Chen, J. Solla-Gullon, S.G. Sun, J.M. Feliu, Electrochim. Acta 55 (2010) 7982. [29] F.J. Vidal-Iglesias, J. Solla-Gullon, E. Herrero, A. Aldaz, J.M. Feliu, Angew. Chem. Int. Ed. 49 (2010) 6998.

[30] F.J. Vidal-Iglesias, A. Lopez-Cudero, J. Solla-Gullon, J.M. Feliu, Angew. Chem. Int. Ed. 52 (2013) 964.

[31] A. Saez, E. Exposito, J. Solla-Gullon, V. Montiel, A. Aldaz, Electrochim. Acta 63 (2012) 105.

[32] C. Buso-Rogero, J.V. Perales-Rondon, M.J.S. Farias, F.J. Vidal-Iglesias, J. SollaGullon, E. Herrero, J.M. Feliu, Phys. Chem. Chem. Phys. 16 (2014) 13616.

[33] F.J. Vidal-Iglesias, R.M. Aran-Ais, J. Solla-Gullon, E. Herrero, J.M. Feliu, ACS Catal. 2 (2012) 901.

[34] H. Massong, S. Tillmann, T. Langkau, E.A.A. Elmeguid, H. Baltruschat, Electrochim. Acta 44 (1998) 1379.

[35] E. Mostafa, A.A. Abd-El-Latif, R. Ilsley, G. Attard, H. Baltruschat, Phys. Chem. Chem. Phys. 14 (2012) 16115.

[36] G. Stalnionis, L. Tamasauskaite-Tamasiunaite, V. Pautieniene, A. Sudavicius, Z. Jusys, J. Solid State Electrochem. 8 (2004) 892.

[37] E. Herrero, V. Climent, J.M. Feliu, Electrochem. Commun. 2 (2000) 636.

[38] A. Ferre-Vilaplana, R. Gisbert, E. Herrero, Electrochim. Acta 125 (2014) 666.

[39] D.A.J. Rand, R. Woods, J. Electroanal. Chem. 35 (1972) 209.

[40] R. Gómez, J.M. Feliu, Electrochim. Acta 44 (1998) 1191. 
[41] R. Gómez, F.J.G. de Dios, J.M. Feliu, Electrochim. Acta 49 (2004) 1195.

[42] F. Maillard, G.Q. Lu, A. Wieckowski, U. Stimming, J. Phys. Chem. B 109 (2005) 16230.

[43] Z.D. Wei, L.L. Li, Y.H. Luo, C. Yan, C.X. Sun, G.Z. Yin, P.K. Shen, J. Phys. Chem. B 110 (2006) 26055.

[44] J. Clavilier, J.M. Orts, J.M. Feliu, A. Aldaz, J. Electroanal. Chem. 293 (1990) 197.

[45] S. Chumillas, C. Busó-Rogero, J. Solla-Gullón, F.J. Vidal-Iglesias, E. Herrero, J.M. Feliu, Electrochem. Commun. 13 (2011) 1194.

[46] N.R. de Tacconi, R.O. Lezna, B. Beden, F. Hahn, C. Lamy, J. Electroanal. Chem. 379 (1994) 329.

[47] J. Souza-Garcia, E. Herrero, J.M. Feliu, ChemPhysChem 11 (2010) 1391.

[48] E. Herrero, K. Franaszczuk, A. Wieckowski, J. Electroanal. Chem. 361 (1993) 269.

[49] M. Bełtowska-Brzezinska, T. Łuczak, J. Stelmach, R. Holze, J. Power Sources 251 (2014) 30.

[50] S. Uhm, S.T. Chung, J. Lee, Electrochem. Commun. 9 (2007) 2027.

[51] M. Watanabe, S. Motoo, J. Electroanal. Chem. 60 (1975) 267.

[52] P.A. Christensen, S.W.M. Jones, A. Hamnett, J. Phys. Chem. C 116 (2012) 24681.

[53] S.C.S. Lai, M.T.M. Koper, Faraday Discuss. 140 (2008) 399. 


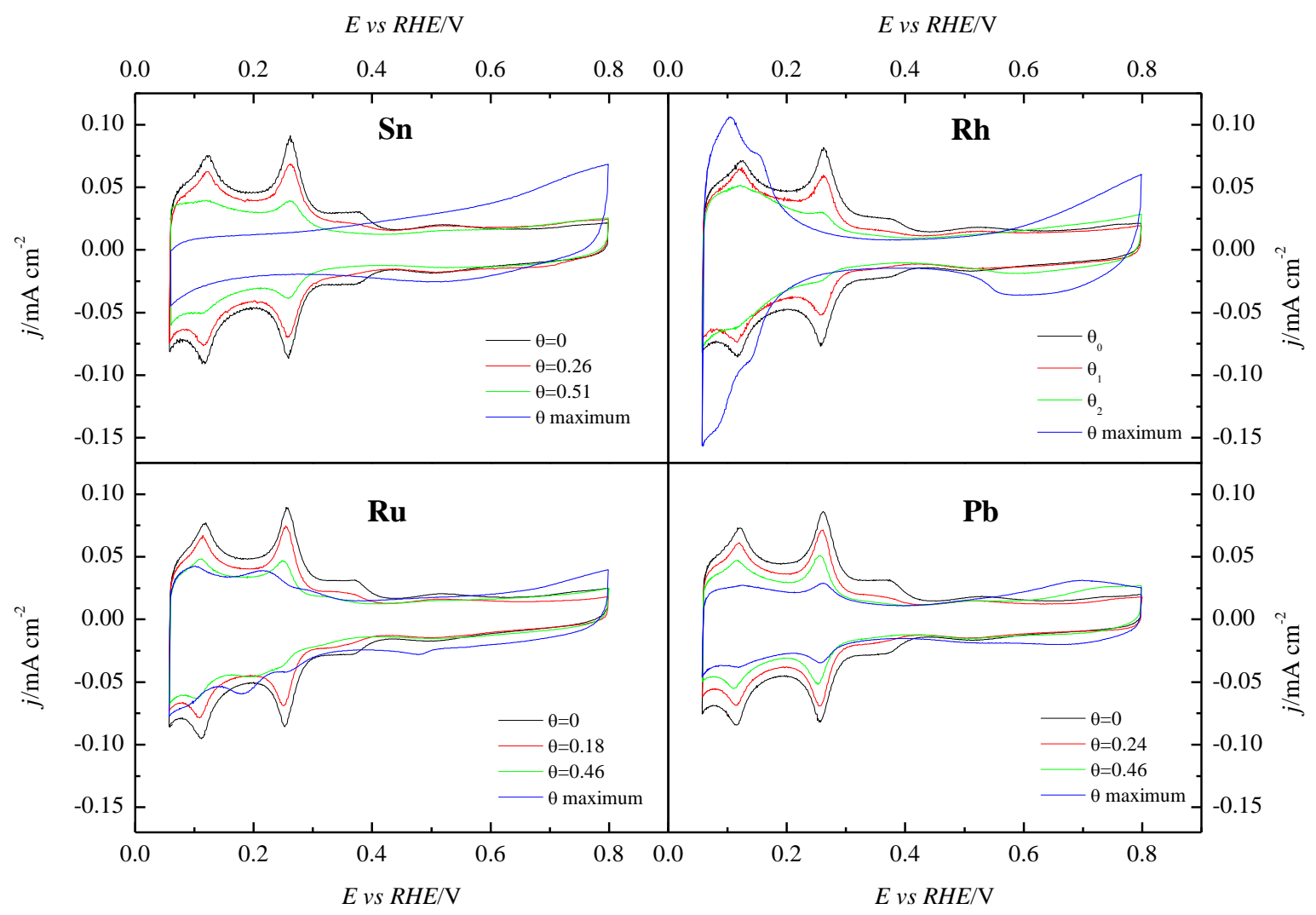

Figure 1. Voltammetric profiles for different adatoms and coverages in (100) Pt nanoparticles. Test solution: $0.5 \mathrm{M} \mathrm{H}_{2} \mathrm{SO}_{4}$. Scan rate: $0.05 \mathrm{~V} \mathrm{~s}^{-1}$. 


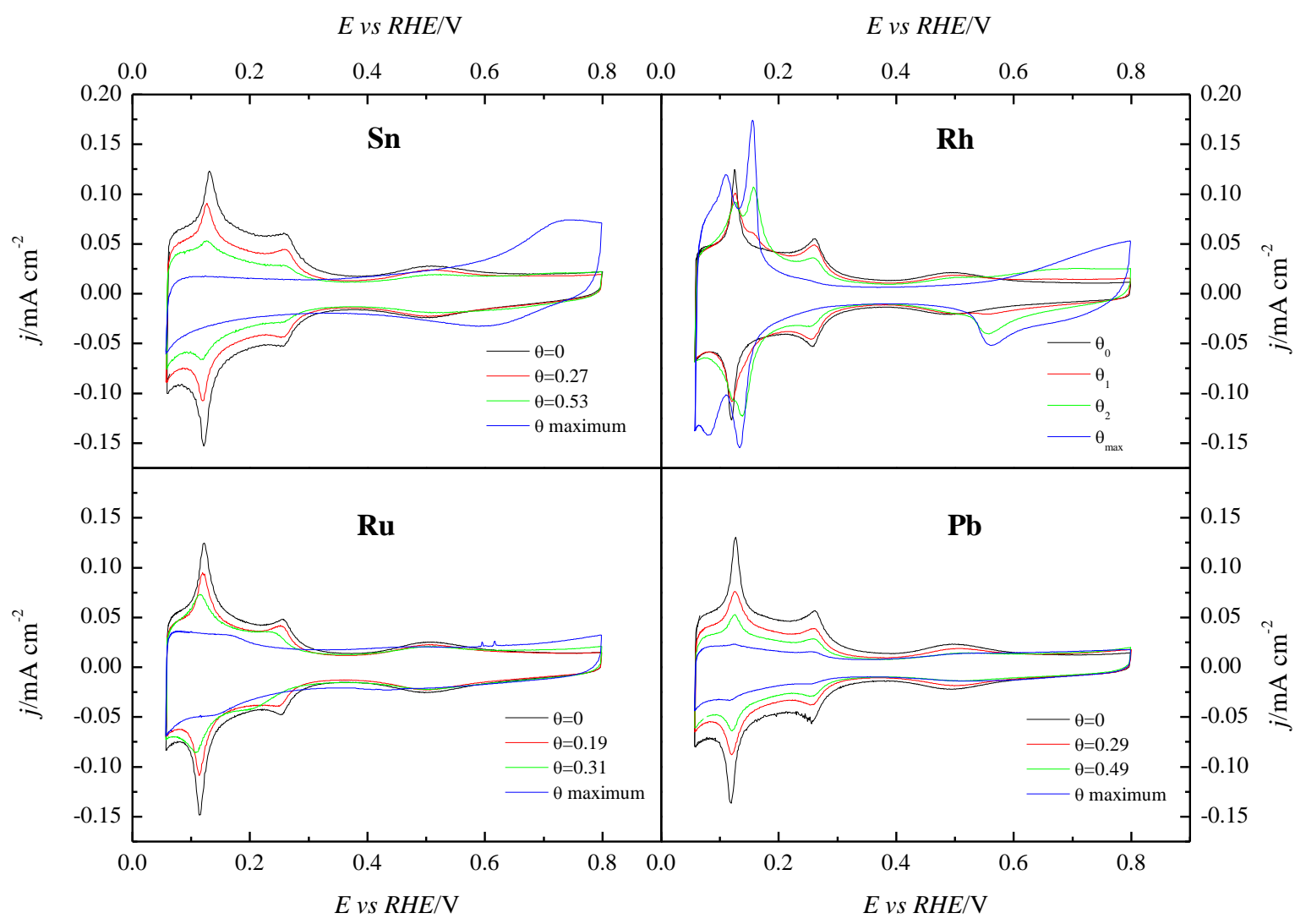

Figure 2. Voltammetric profiles for (111) Pt nanoparticles modified by different adatoms in $0.5 \mathrm{M} \mathrm{H}_{2} \mathrm{SO}_{4}$ at $0.05 \mathrm{~V} \mathrm{~s}^{-1}$. 


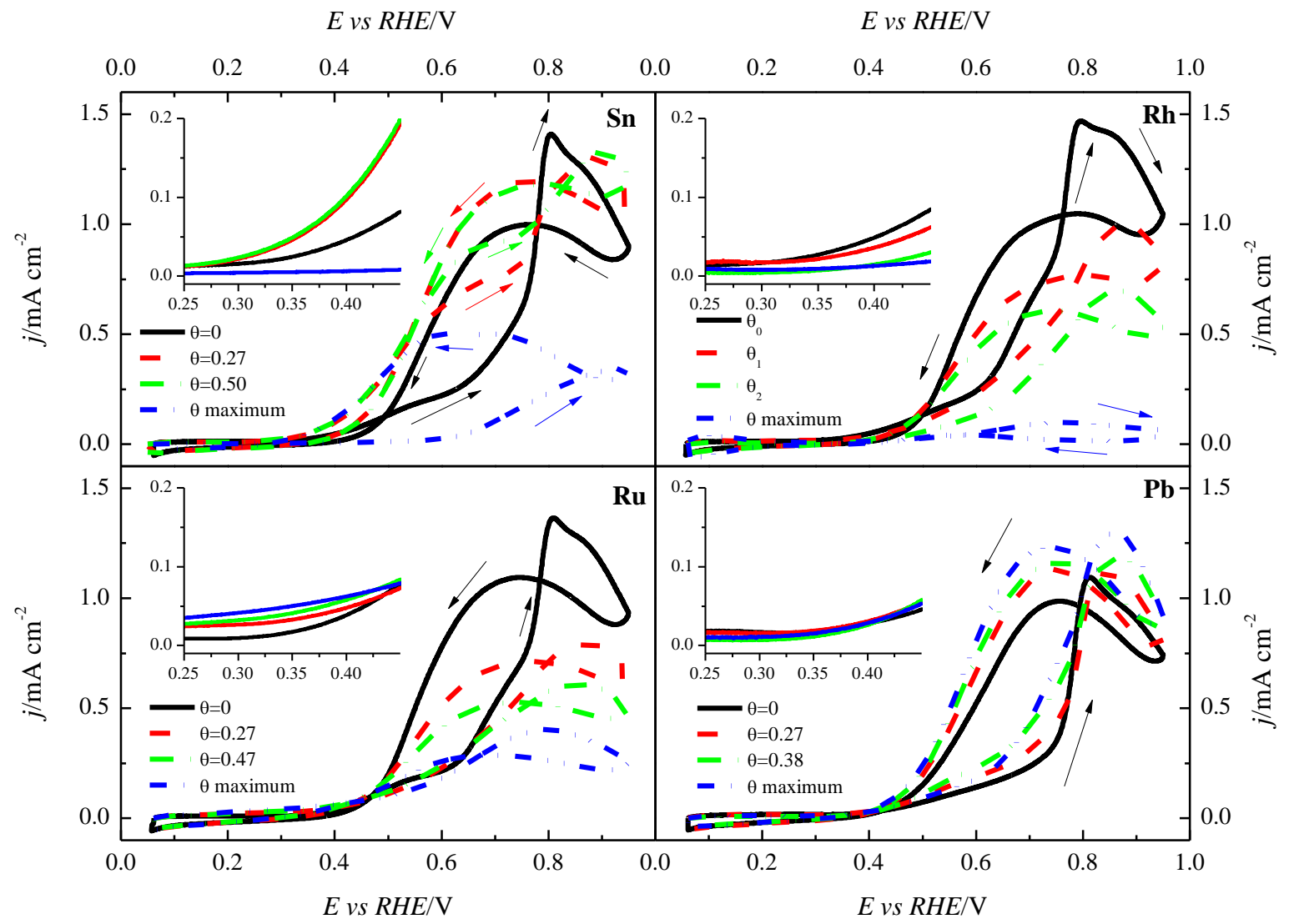

Figure 3. Voltammetric profiles for (100) Pt nanoparticles modified by $\mathrm{Sn}, \mathrm{Rh}, \mathrm{Ru}$ and $\mathrm{Pb}$ in $0.2 \mathrm{M}$ ethanol $+0.5 \mathrm{M} \mathrm{H}_{2} \mathrm{SO}_{4}$ at $0.02 \mathrm{~V} \mathrm{~s}^{-1}$. Inset: Currents for positive scan direction in the onset potential region. 


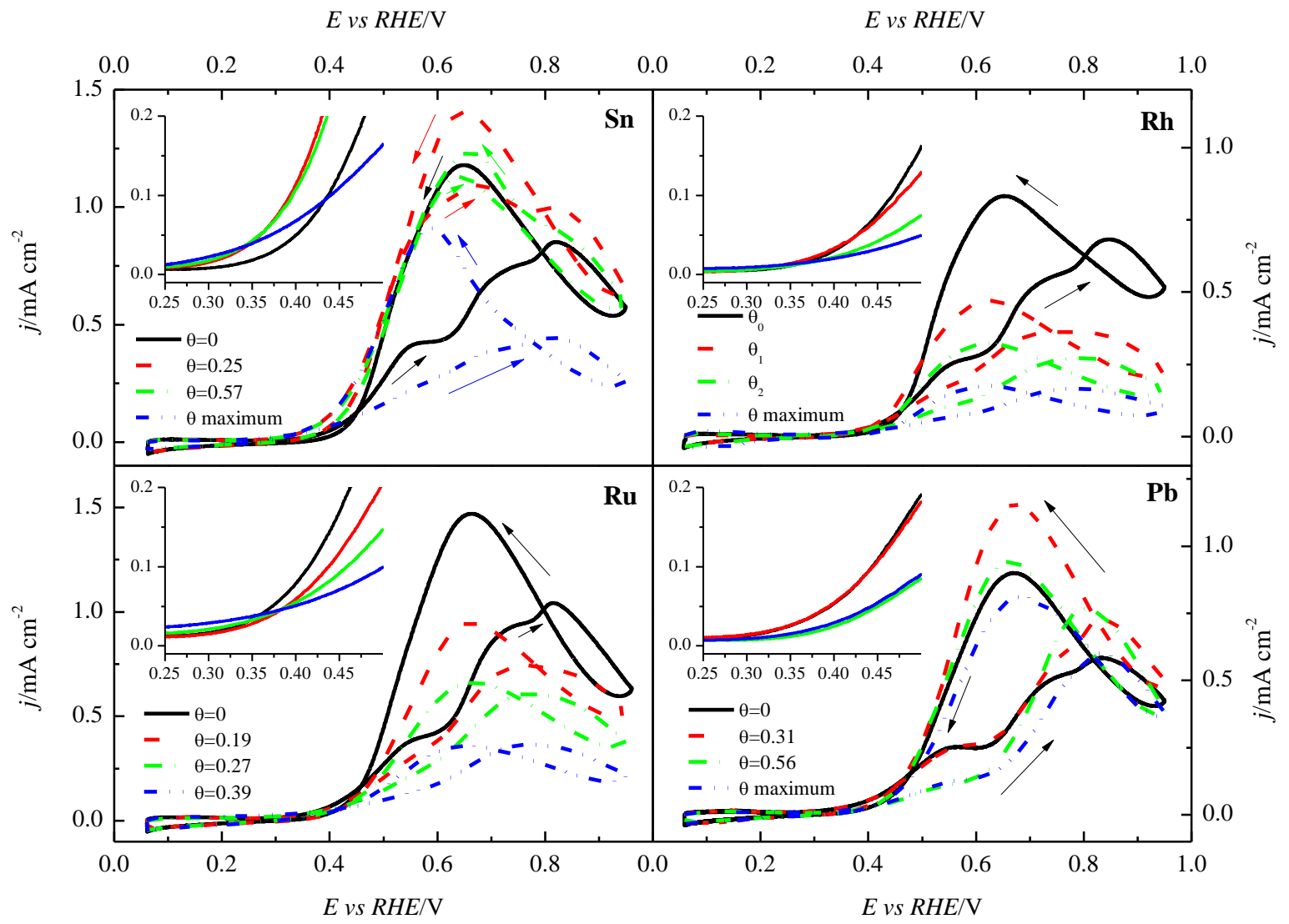

Figure 4. Voltammetric profiles for ethanol oxidation on (111) Pt nanoparticles modified by $\mathrm{Sn}, \mathrm{Rh}, \mathrm{Ru}$ and $\mathrm{Pb}$ in $0.2 \mathrm{M}$ ethanol $+0.5 \mathrm{M} \mathrm{H}_{2} \mathrm{SO}_{4}$. Scan rate: $0.02 \mathrm{~V} \mathrm{~s}^{-1}$. Inset: Currents for positive scan direction in the onset potential region. 


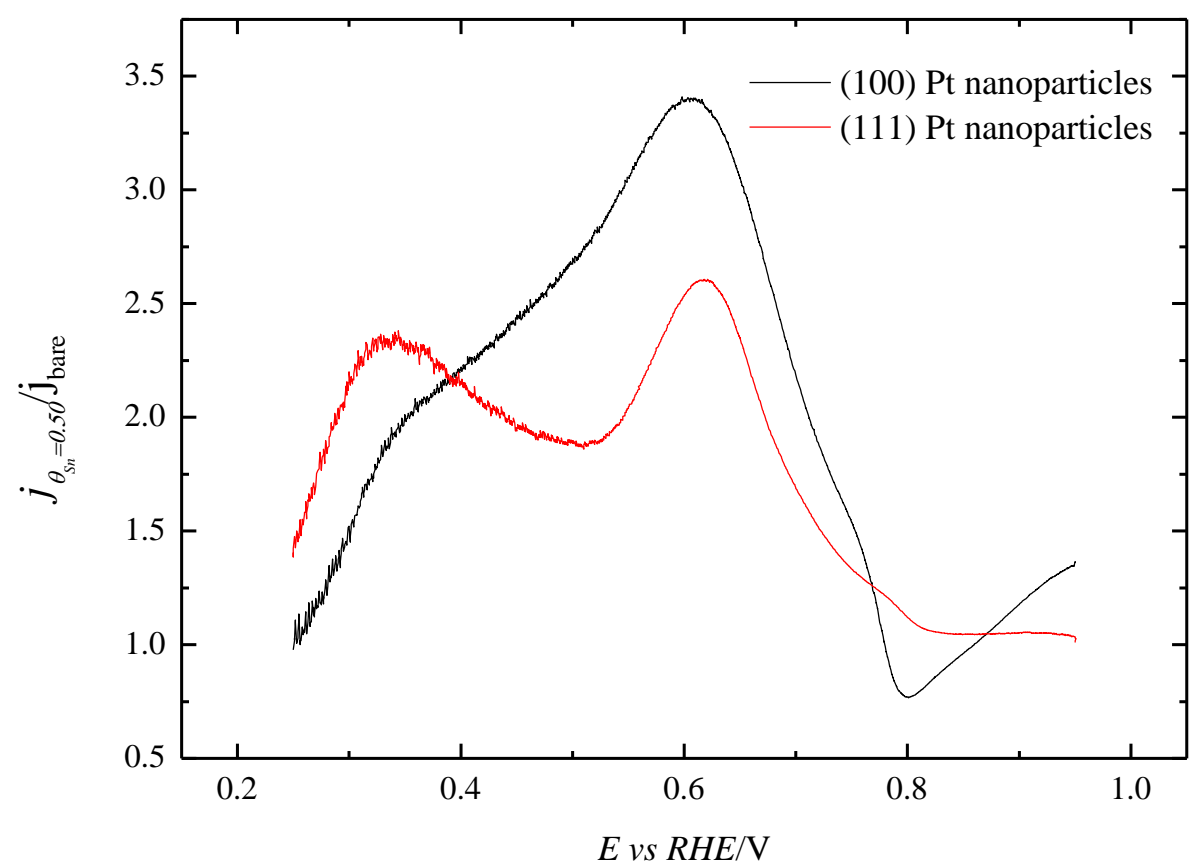

Figure 5. Ratio between ethanol oxidation current densities obtained for the bare and Sn-decorated (coverage around 0.5) shape-controlled platinum nanoparticles in the positive scan direction. Data taken from the tin experiments of Figs. 3 and 4. 

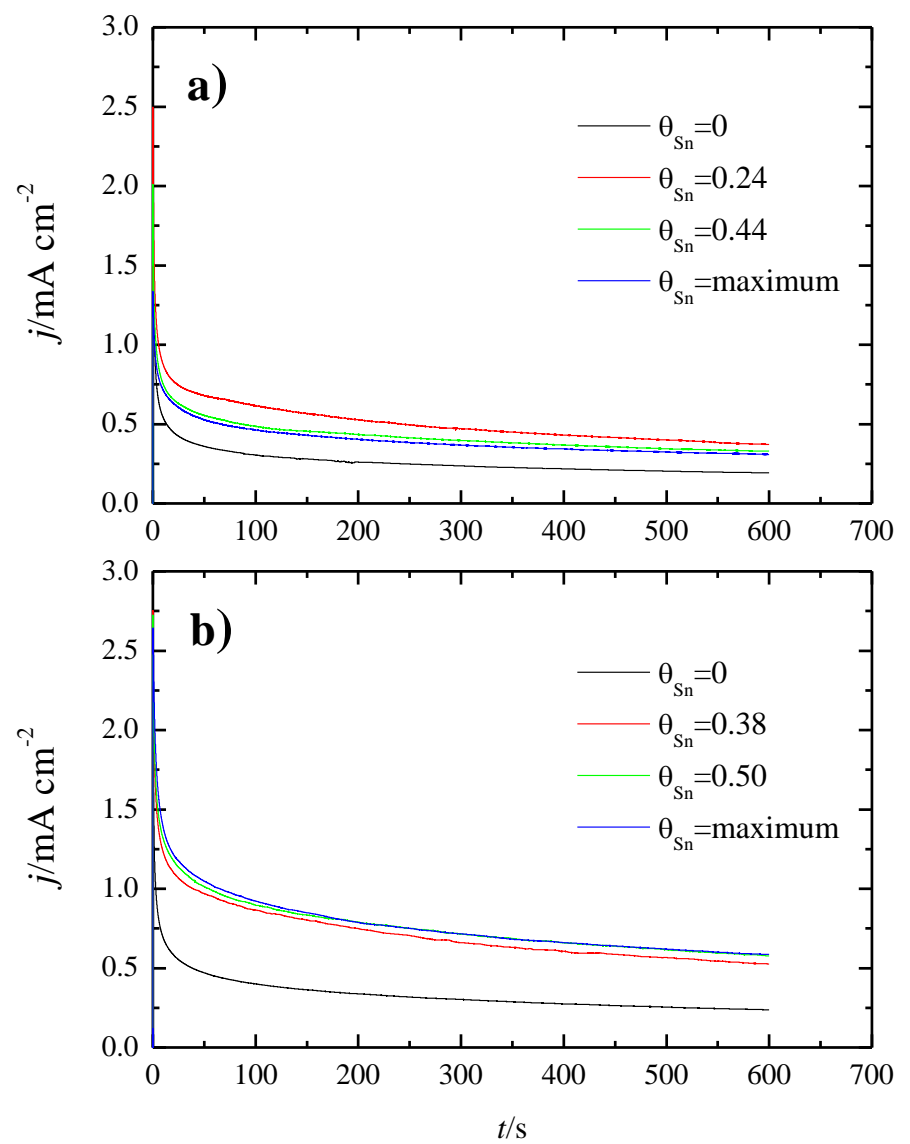

Figure 6. Chronoamperometric response at $0.6 \mathrm{~V}$ for $0.2 \mathrm{M}$ ethanol $+0.5 \mathrm{M} \mathrm{H}_{2} \mathrm{SO}_{4}$ in: a) (100) Pt and b) (111) Pt nanoparticles modified with different coverages of Sn. 


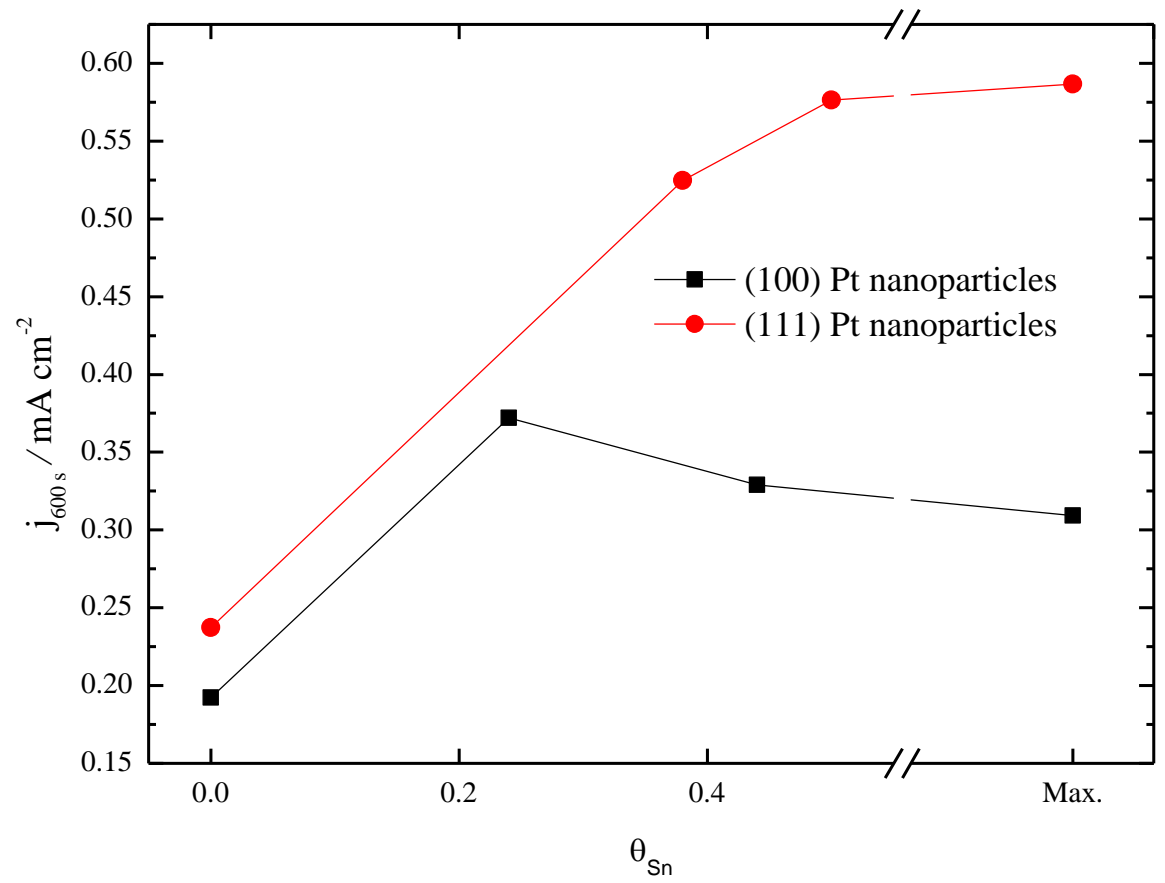

Figure 7. Current densities measured after $600 \mathrm{~s}$ in Fig. 6 vs tin coverage for Sndecorated shape-controlled Pt nanoparticles. 


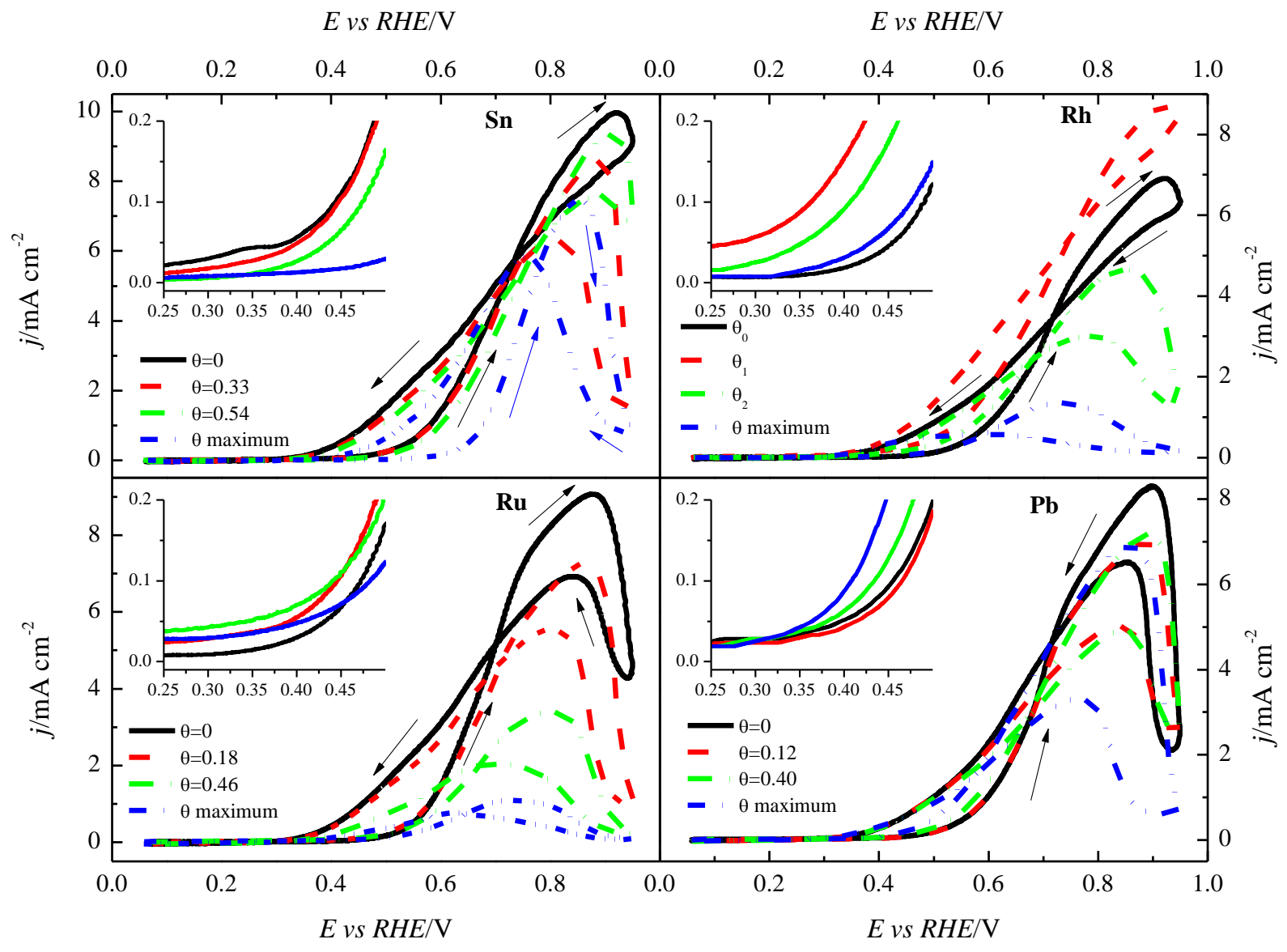

Figure 8. Voltammetric profiles for ethanol oxidation on (100) Pt nanoparticles modified by $\mathrm{Sn}, \mathrm{Rh}, \mathrm{Ru}$ and $\mathrm{Pb}$ in $0.2 \mathrm{M}$ ethanol $+0.1 \mathrm{M} \mathrm{NaOH}$. Scan rate: $0.02 \mathrm{~V} \mathrm{~s}^{-1}$. Inset: Currents for positive scan direction in the onset potential region. 


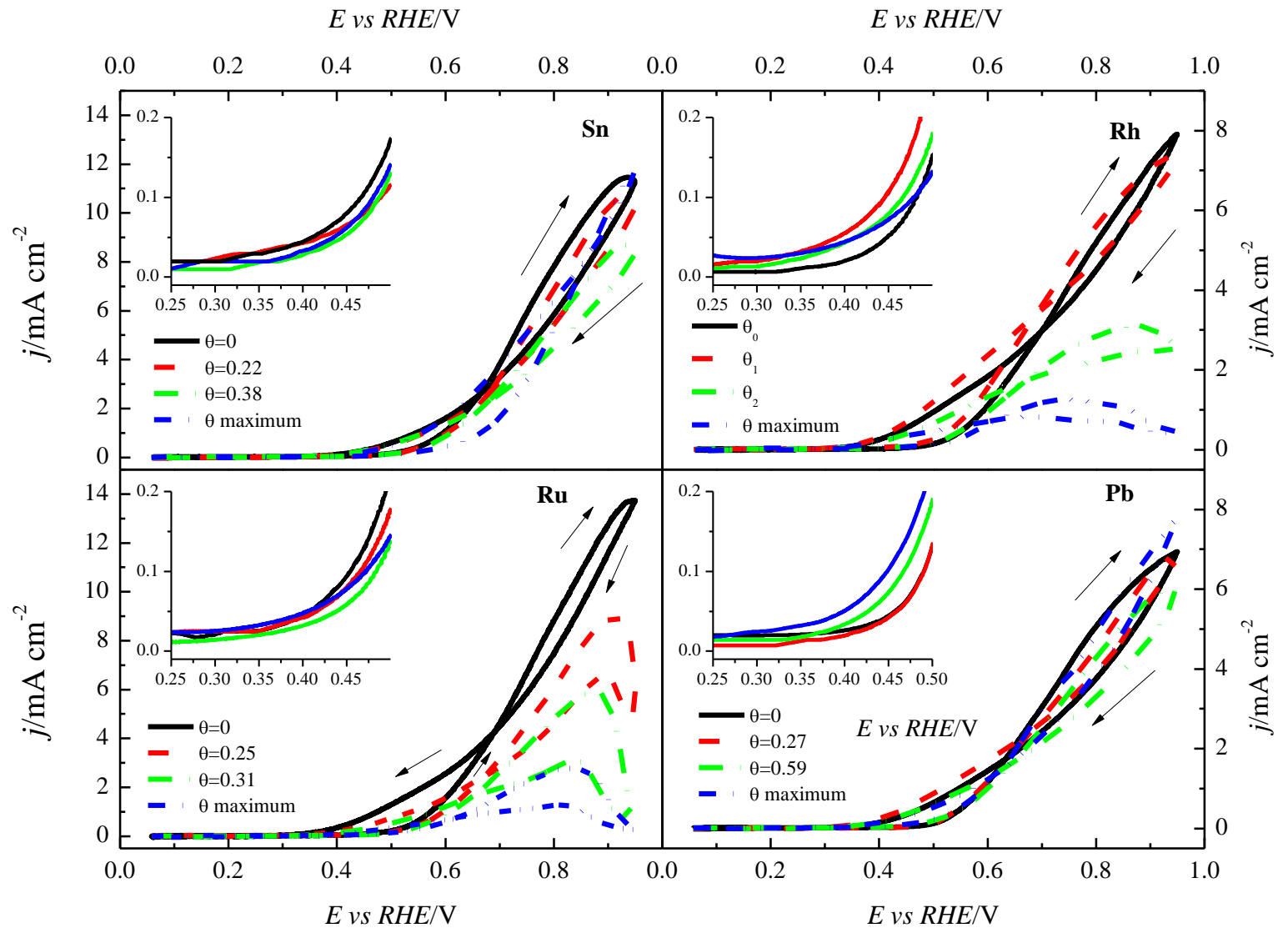

Figure 9. Voltammetric profiles for ethanol oxidation on (111) Pt nanoparticles modified by $\mathrm{Sn}, \mathrm{Rh}, \mathrm{Ru}$ and $\mathrm{Pb}$ in $0.2 \mathrm{M}$ ethanol $+0.1 \mathrm{M} \mathrm{NaOH}$. Scan rate: $0.02 \mathrm{~V} \mathrm{~s}^{-1}$. Inset: Currents for positive scan direction in the onset potential region. 